\title{
Effect of Exposure of Ultraviolet B Radiation on Two Anuran Species, Polypedates cruciger and Duttaphrynus melanostictus under Empirical Conditions
}

\author{
Uthpala A. Jayawardena ${ }^{1,2}$, Ayanthi N. Navaratne ${ }^{3}$, Priyanie H. Amerasinghe ${ }^{4}$ and \\ Rupika S. Rajakaruna ${ }^{1^{*}}$ \\ ${ }^{1}$ Department of Zoology, University of Peradeniya, Peradeniya, Sri Lanka. \\ ${ }^{2}$ Postgraduate Institute of Science, University of Peradeniya, Peradeniya, Sri Lanka. \\ ${ }^{3}$ Department of Chemistry, University of Peradeniya, Peradeniya, Sri Lanka. \\ ${ }^{4}$ International Water Management Institute, c/o ICRISAT, Patancheru - 502 \\ 324, Hyderabad, Andhra Pradesh, India. \\ Accepted November 22, 2013
}

\begin{abstract}
Increase in ultraviolet (UV)-B radiation has been identified as a suspect in amphibian deformities and decline. Eggs of two amphibian species, Polypedates cruciger and Duttaphrynus melanostictus were exposed to UV-B radiation $(312 \mathrm{~nm})$ to receive erythemal dose $(0.08$ relative response) of the action spectra under laboratory conditions. Biologically estimated doses were calculated to match 50\% (high), 25\% (medium) and 10\% (low) of the average daily irradiance given for the Asian region $\left(17.92 \times 10^{-3} \mathrm{Wm}^{-2}\right)$. Hatching success of the eggs and survival, growth of tadpoles and development of malformations were recorded until metamorphosis. Although the exposure had no effect on the hatching success of the eggs of the two species, the survival of tadpoles of both species was significantly reduced compared to the tadpoles coming from unexposed eggs in the control. Tadpoles of both species experienced growth retardations due to UV-B exposure. Exposed individuals were smaller at metamorphosis and they took longer to metamorphose. In addition, malformations such as ulcers, edemas, abnormally pigmented skin were common among the exposed tadpoles. Species-specific differences in the growth were observed between $D$. melanostictus and P. cruciger but not in the other measured parameters. This study shows that the two anuran species are highly sensitive to levels of UV-B radiation that is present in their natural environment and suffered both lethal and sub-lethal effects.
\end{abstract}

Keywords: survival, growth, malformations, hatching success

\section{INTRODUCTION}

Depletion of the stratospheric ozone due to anthropogenic activities affects the natural shield of the earth against harmful ultraviolet (UV) radiation, especially UV-B radiation (Kerr and McElroy, 1993). This is considered as a matter of importance and it was recommended that urgent research be conducted to examine the effects of increased UV-B radiation on organisms. In this context, amphibians are likely to be more susceptible than most other taxa due to their lifecycle strategies. Amphibians lay unshelled eggs which are often exposed to direct sunlight and the larvae develop in the same environment. Many amphibian species prefer clear water with intense solar irradiance and low riparian cover making them even more vulnerable to radiation (Langhelle et al., 1999). The potential impacts of UV-B radiation on animals act mainly on their physiology by means of DNA damage, direct protein damage and by producing oxygen free radicals (Formicki et al., 2003). The ultimate effect of this damage is cell death (Jurkiewicz and Buettner, 1994). Apart from these direct effects, amphibians particularly suffer the consequences of low oxygen consumption which might affect their survival by restricting behavioral responses such as anti-predator behavior, thermoregulation and foraging (Formicki et al., 2003). Furthermore, the synergistic effect of UV-B and other natural factors such as pathogenic fungi and pesticides too, act as additional stress factors (Hatch and Blaustein, 2000).

Ultraviolet -B radiation present in natural sunlight can increase the mortality and malformation rates in embryos of amphibians (Blaustein et al., 1999). In the early stages UV-B has been reported to cause higher mortality in Bufo boreas and Rana

*Corresponding author's email: rupikar@pdn.ac.lk 
cascadae in North America (Blaustein et al., 1994). Tadpoles of two other North American species, Hyla regilla and $R$. auroa exposed to UV$B$ radiation developed lens opacities (cataracts) and skin burns under laboratory settings (Flamarique et al., 2000). A laboratory simulation of UV-B in B. bufo tadpoles was reported to decrease oxygen consumption, which in turn may affect development and defense against stochastic stress factors (Formicki et al., 2003). Furthermore, these authors reported that eggs under UV-B shields had a higher hatching rate (85\%,vs. $65 \%$ in embryos exposed to UV-B), fewer deformities (19\%, vs.21\%) and show more rapid development than those exposed to UV-B. Many such studies have focused on early life stages of amphibians, during which the most critical developmental processes take place. Upon the exposure to UV radiation $R$. pipiens showed bilateral ectromelia and ectrodactyly in the hind limbs of developing tadpoles (Ankley et al., 1998). The same authors later revealed that direct sunlight caused approximately 50\% mortality during early larval development of $R$. pipiens (Ankley et al., 2002). These studies suggest that damage caused by UV radiation in amphibians may differ among species. Amphibians live in habitats which are constantly exposed to UV radiation are more tolerant compared to those exposed to UV intermittently (Blaustein et al., 1999).

Trematode infections, ultraviolet radiation and biocides have all been identified as major causes of amphibian malformations (Ankley et al., 2002; Blaustein and Johnson, 2003; Johnson et al., 1999; Kiesecker, 2002). Recent reports of malformed frogs from a nature reserve in Sri Lanka (Rajakaruna et al., 2007) led to laboratory studies exploring the effect of pesticides (Jayawardena et al., 2010; 2011) and parasites (Rajakaruna et al., 2008; Jayawardena et al., 2010; 2013). Tadpoles of Polypedates cruciger (common hour glass tree frog) and Duttaphrynus melanostictus (Asian common toad) exposed to these stress factors developed severe malformations, leading to high mortality. More recently, Wijesinghe et al. (2011) investigated the potential of natural solar radiation to alter the toxicity of carbofuran, a commonly used carbamate pesticide, on tadpoles of $D$. melanostictus, showing that photo-irradiation markedly reduced the toxicity of carbofuran as evident by its effects on mortality, growth and swimming activity.

Polypedates cruciger and D. melanostictus are widely distributed amphibians in Sri Lanka, predominantly in human altered habitats in the island's south-western wet zone. The tadpoles of P. cruciger and D. melanostictus develop in clear ponds and pools that are directly exposed to the sun. Here we investigate the effect of biologically estimated doses (BED) of UV-B radiation on the hatching success, survival, growth and malformations of the tadpoles of $P$. cruciger and D. melanostictus under laboratory conditions.

\section{MATERIALS AND METHODS}

Eggs of $P$. cruciger and D. melanostictus were collected from ponds and pools in the Peradeniya University Park (Sri Lanka). Each egg clutch (Gosner 11-12) was separated into four masses having a similar number of eggs in each mass (approximately 50 eggs). Egg masses of $P$. cruciger were attached to the wall of a glass trough containing $500 \mathrm{~mL}$ of dechlorinated tap water while egg strands of $D$. melanostictus were submerged in similar troughs containing the same amount of water.

Biologically estimated doses (BED) of radiation for the exposure were calculated (Table 1).The doses were estimated such that the UV lamp mimics 50\% (high), 25\% (medium) and 10\% (low) of the total irradiance $(\approx 258 \mathrm{kJm}-2)$, expected in Sri Lanka, daily for a period of four hours (10.00-14.00 hr). Eggs of both species were exposed to a $312 \mathrm{~nm}$ UV lamp (VL-115 M, Vilber Lourmat, spectral region 280-320 nm, spectral peak $312 \mathrm{~nm}, 30 \mathrm{~W}$ ) inside a UV chamber. The UV source was placed at $30 \mathrm{~cm}$ above the water level to give a surface irradiance of $2.5 \mathrm{Wm}-2$ (Table 1). The exposure was done in 12:12 hr light: dark cycles. Hence, after the UV exposure tadpoles were exposed to full spectrum florescence light to complete the $12 \mathrm{hr}$ light period. This exposure was continued daily until metamorphosis. Throughout the experiment the $\mathrm{pH}$ of the medium was kept constant by renewing the water on a daily basis. Soon after hatching, the number of tadpoles in each setup was recorded and hatching success calculated by dividing the number of hatched tadpoles by the initial number of eggs in each (20-30) exposure. Mortality was recorded daily and the snout vent length (SVL) and the body weight of the metamorphs were measured. Metamorphs were observed under binocular microscope and malformations were recorded. The malformed individuals were first euthanized in MS222 and then preserved in 70\% alcohol for further investigations. Survival of the tadpoles was calculated as a percentage of successfully hatched tadpoles that survived to 
metamorphosis. The time required for forelimb emergence of half the number of tadpoles $\left(\mathrm{TE}_{50}\right)$ in a particular regime was calculated and used as a measure for assessing the length of the development period. The experiment was repeated four times per species using separate egg clutches $(\mathrm{n}=487$ for $D$. melanostictus and $\mathrm{n}=342$ for $P$. cruciger).

Data were analyzed using MINITAB 14.0 for Windows. The existence of a linear relationship between different doses of UV-B radiation and hatching success, survival, growth parameters and development of malformations was tested using a Pearson correlation. The effect of different doses of UV-B radiation on hatching success, survival, growth parameters and development of malformations was analyzed using one-way ANOVA (analysis of variance) and individual comparisons were made using Tukey post hoc test (Sokal and Rohlf 1999). The differences in hatching success, survival, growth parameters and malformations between the two anuran species were compared using an analysis of co-variance (ANCOVA).

\section{RESULTS}

\section{Hatching success}

The eggs of both species began hatching within 3-5 days after exposure (Figure 1a). Although the hatching success decreased with increasing radiation dose, there was no significant correlation in both species (Pearson correlation; P. cruciger, $\mathrm{r}=-0.278, \mathrm{p}=0.722 ; D$. melanostictus, $\mathrm{r}=-0.378, \mathrm{p}=0.622$ ). The decrease in hatching success was not consistent in P. cruciger (Fig. 1a). Exposure to UV-B had no effect on the hatching success of in the exposed eggs of both species (One way ANOVA, df $=3, \mathrm{p}>0.05$ ). Moreover, there was no significant difference in the overall hatching success between the two species (ANCOVA; $\mathrm{F}_{1,3}=2.66, \mathrm{p}=0.119$ ).

Table 1. Different exposure regimes and dose estimation at each regime of the study.

\begin{tabular}{lccccc}
\hline $\begin{array}{c}\text { Exposure } \\
\text { Regime }\end{array}$ & $\begin{array}{c}\text { Percentage of } \\
\text { total daily } \\
\text { dose* }(\%)\end{array}$ & $\begin{array}{c}\text { Total dose } \\
\left(\mathrm{kJm}^{-2}\right)\end{array}$ & $\begin{array}{c}\text { Time of } \\
\text { irradiance } \\
(\mathrm{sec})\end{array}$ & $\begin{array}{c}\text { Biologically } \\
\text { estimated dose } \\
\left(\mathrm{BED}, \mathrm{kJm}^{-2}\right)\end{array}$ & $\begin{array}{c}\text { Treatment no. } \\
\text { given in } \\
\text { Figures } 1 \& 2\end{array}$ \\
\hline Control & 0 & -- & -- & 0 & 1 \\
Low & 10 & 25.8 & 10 & $1.5 \times 10^{-2}$ & 2 \\
Medium & 25 & 64.5 & 26 & $3.8 \times 10^{-2}$ & 3 \\
High & 50 & 129.0 & 52 & $7.6 \times 10^{-2}$ & 4
\end{tabular}

* Total daily dose $\left(258.048 \mathrm{kJm}^{-2}\right)$ was estimated by multiplying mean intensity of UV $\left(17.92 \times 10^{-3} \mathrm{Wm}^{-2}\right)$ by 14,400 sec. (for a period of $4 \mathrm{hr}$ during day time (10 a.m.-2 p.m.). A $60 \mathrm{~W}$ white light fluorescent bulb was used for the control group.

(a)

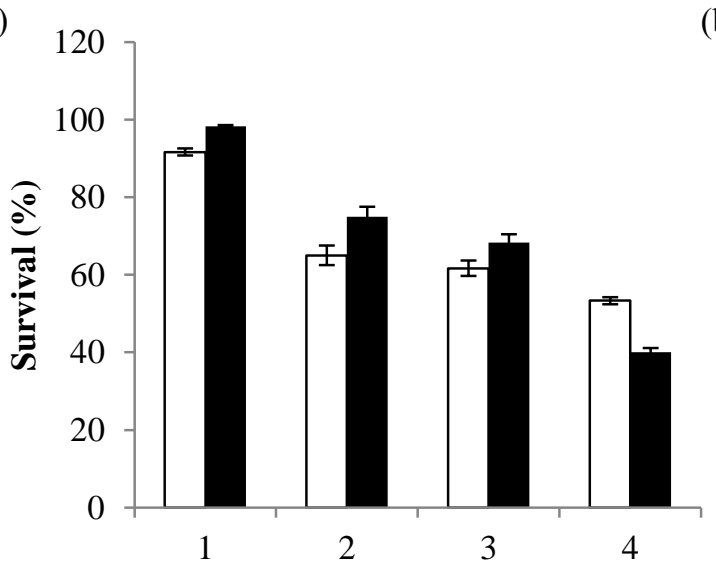

Biologically weighted dose $\left(\mathrm{kJ} \mathbf{~ m}^{-2}\right)$

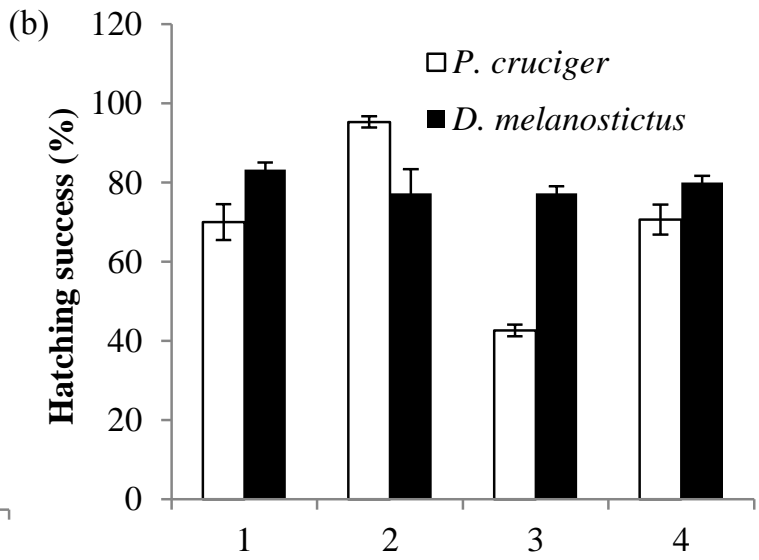

Biologically weighted dose $\left(\mathrm{k} \mathrm{Jm}^{-2}\right)$

Figure 1. (a) Hatching success of eggs and (b) survival of tadpoles of P. cruciger and D. melanostictus, exposed to UV-B radiation $(312 \mathrm{~nm})$ at different exposure regimes with the standard error of the mean. 


\section{Survival}

The percentage survival of the metamorphs decreased with increasing radiation dose (Fig. 1b) showing a statistically significant linear relationship in D. melanostictus, (Pearson correlation, $\mathrm{r}=-0.960, \mathrm{p}=0.040)$ but not in $P$. cruciger (Pearson correlation, $\mathrm{r}=-825, \mathrm{p}=0.175$ ). However, exposure to UV had a significant effect on the survival of tadpoles of both species (One way ANOVA, $\mathrm{df}=3, \mathrm{p}<0.05)$. Individual comparisons between different doses and control showed significantly lower survival in all the exposed tadpoles of both species (Tukey's post hoc test, $\mathrm{df}=1, \mathrm{P}<0.05$ ). There was no significant difference in the survival of tadpoles between the two species (ANCOVA; $\mathrm{F}_{1,3}=0.17, \mathrm{p}=0.681$ ).

\section{Growth}

All three parameters of growth (SVL, weight and $\mathrm{TE}_{50}$ ) were affected in the two species exposed to radiation. The overall growth was retarded and the metamorphs that emerged were smaller than those of the control (Fig. 2). Although there was a decrease in growth parameters with increase in the dose, the relationship was not linear (Pearson correlation; SVL of $P$. cruciger, $\mathrm{r}=-0.782, \mathrm{p}=$ $0.218, \mathrm{SVL}$ of $D$. melanostictus, $\mathrm{r}=-0.745, \mathrm{p}=$ 0.255 ; weight of $P$. cruciger, $\mathrm{r}=-0.866, \mathrm{p}=0.134$, weight of $D$. melanostictus, $\mathrm{r}=-0.826, \mathrm{p}=0.174$ ). Radiation exposure had a significant effect on the size of both species compared to that of the nonexposed animals in the control groups (One way

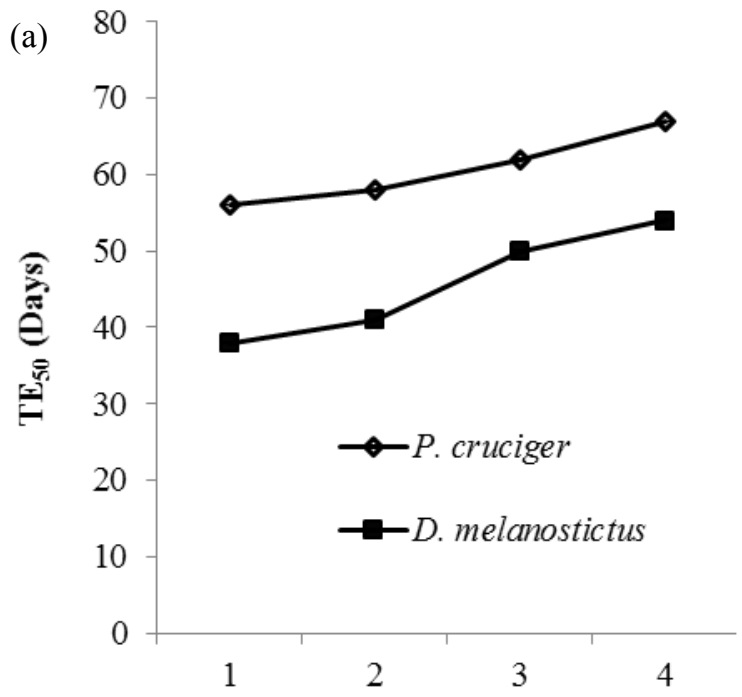

Biologically weighted dose $\left(\mathrm{k} \mathrm{Jm}^{-2}\right)$
ANOVA; $P$. cruciger- SVL $\mathrm{F}_{3,164}=175.86$ $\mathrm{p}<0.001$, body weight $\mathrm{F}_{3,164}=71.3, \mathrm{p}<0.001$, and D. melanostictus- SVL $\mathrm{F}_{1,164}=97.87, \mathrm{p}<0.001$, body weight, $\left.F_{1,164}=27.00, p<0.001\right)$. Individual comparisons between different doses showed that exposed tadpoles of both species were significantly smaller than those in the control (Tukey's post hoc test, $\mathrm{df}=1, \mathrm{P}<0.05$ ). Between the two species, P. cruciger tadpoles experienced a significantly higher reduction in size compared to D. melanostictus tadpoles (ANCOVA; $\mathrm{p}<$ 0.001). The lengthening of the development period, TE 50 was also higher in UV-B treated animals with average of 67 days for $P$. cruciger (56 days in the control) and 54 days for $D$. melanostictus (32 days in the control).

\section{Malformations}

The malformations were easily detectable to the naked eye. The most common type was edema in the abdominal region. It was more prominent in P. cruciger (Fig. 3a) than in D. melanostictus (Fig. 3d). Tadpoles with edema swam upside down at the water surface. A swollen abdominal region was also observed to be a common malformation in both species (Fig. 3b, e). These specimens possessed distended, prominent and transparent abdomens compared to the normal individuals. Lighter skin color with abnormal pigmentation was observed in exposed $P$. cruciger (Fig. 4).

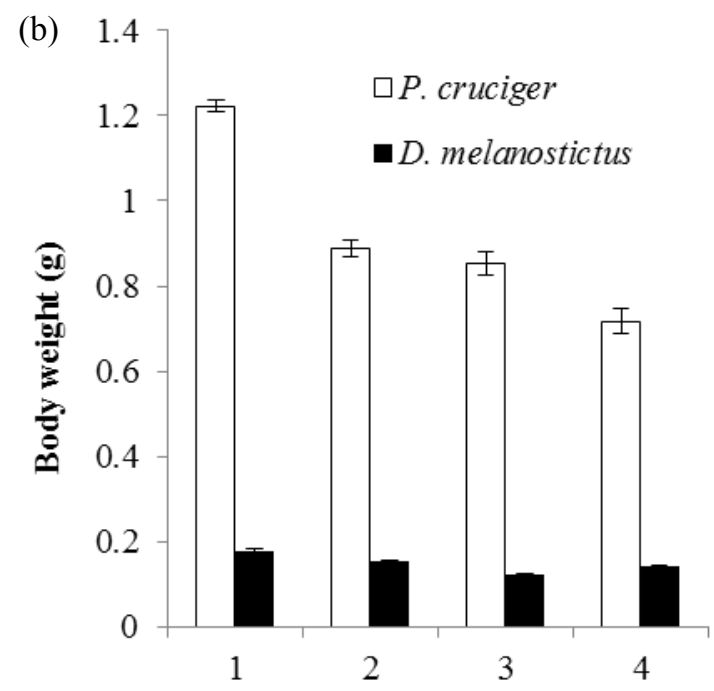

Biologically weighted dose $\left(\mathrm{k} \mathrm{Jm}^{-2}\right)$

Figure 2. (a) Time required for the metamorphosis of half the number of tadpoles in a treatment (TE50) in days and (b) the body weight of the metamorphs in grams of $P$. cruciger and D. melanostictus, exposed to UV-B radiation $(312 \mathrm{~nm})$ at different exposure regimes with the standard error of the mean. $(1=$ the control experiment, $2=1.5 \times 10^{-2}, 3=3.8 \times 10^{-2}, 4=7.6 \times 10^{-2} \mathrm{k} \mathrm{Jm}^{-2}$ ) 
Curvature of the vertebral column was also common to both species (Figure $3 \mathrm{c}$ and f). Exposure to UV-B radiation had a significant effect on inducing malformations in both $P$. cruciger (One-way ANOVA; dose, $\mathrm{F}_{2,12}=6.04, \mathrm{p}=$ 0.037 )and D. melanostictus (ANOVA; dose, $\left.\mathrm{F}_{2,12}=7.09, \mathrm{p}=0.026\right)$. There was no significant difference in the percentage malformations between the two species (ANCOVA; $\mathrm{F}_{1,14}=1.78$, $\mathrm{p}=0.203)$. There were no malformations in any of the control animals.

\section{DISCUSSION}

Exposure to UV $\mathrm{B}$ radiation has a significant effect on the survival, growth and development of malformations in both $P$. cruciger and $D$. melanostictus. UV-B irradiance used in the laboratory corresponds to the average daily dose received in a tropical country on a sunny day (WOUDC, 2007). At the time of the study UV-B intensities of the test area (Peradeniya, Sri Lanka) has not been estimated, hence, measurements for the region $\left(17.92 \times 10^{-3} \mathrm{Wm}^{-2}\right.$, WOUDC, 2007) was taken as the basis for calculation of the exposure time to UV lamps. The biologically estimated doses (BED) were also calculated under the exposure system according to erythema action spectrum. The BED under the UV lamp ranged from $1.5-7.6 \times 10^{-2} \mathrm{kJm}^{-2}$ and this value was substantially low in comparison to several other studies conducted in Europe and America. In most of the studies UV-B intensities were taken as high as $1.5-2.5 \mathrm{kJm}^{-2}$.

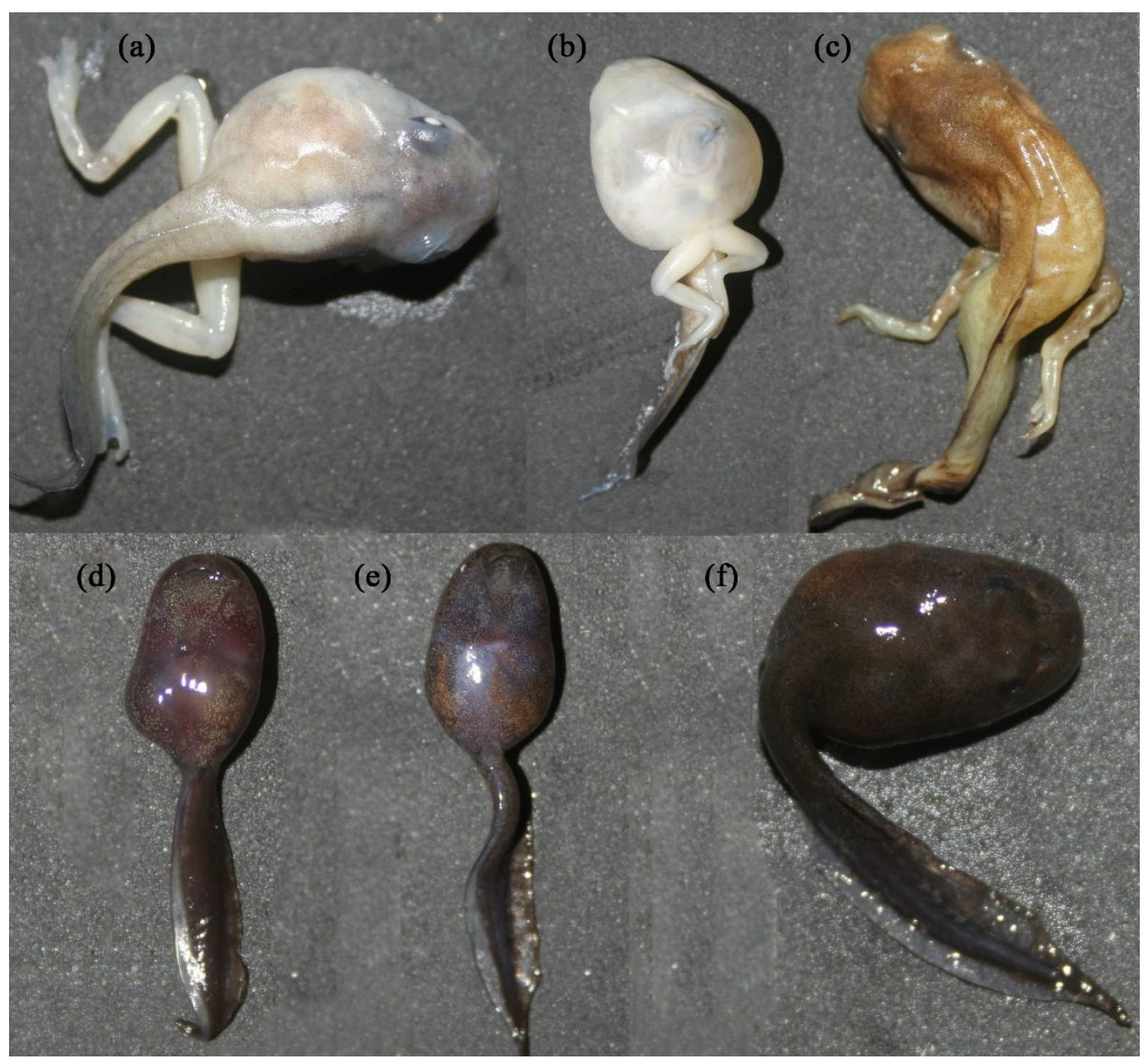

Figure 3. Malformations found in tadpoles of $P$. cruciger and D. melanostictus, exposed to UV-B radiation $(312 \mathrm{~nm})$ at different exposure regimes. (a) Edema at the left side of the body (b) swollen abdomen and (c) curvature at the tail region of $P$. cruciger tadpoles; (d) edema at the right side of the body (e) swollen abdomen and (f) curvature at the tail region of D. melanostictus $(\mathrm{G})$ tadpoles. 


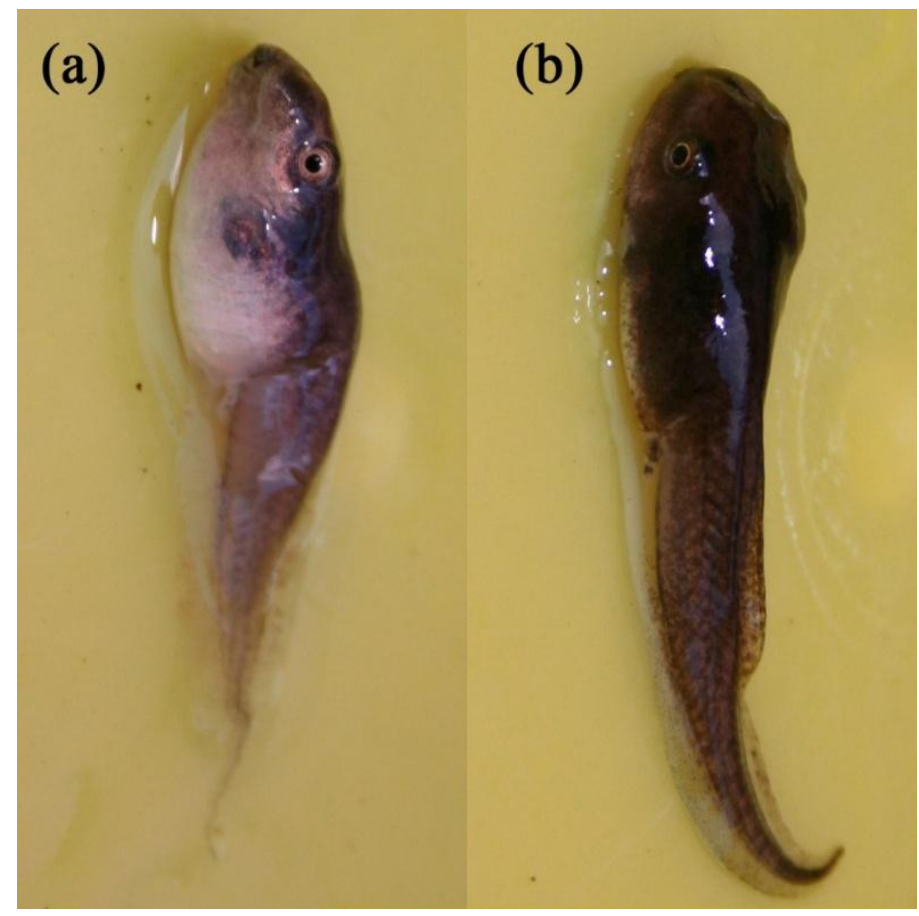

Figure 4. (a) Abnormal pigmentation in $P$. cruciger compared to (b) a normal tadpole of the same species.

Studies have shown that different amphibian species respond differently to exposure to UV radiation. Hatching success of eggs of both $P$. cruciger and D. melanostictus were not affected by exposure to UV-B radiation. Lower hatching success upon exposure to UV radiation has been observed in many amphibian species including Bufo boreas and Rana cascadae (Blaustein et al., 1994), two salamander species Ambystoma gracile (Blaustein et al., 1996) and Ambystoma macrodactylum (Blaustein et al., 1997). The longtoed salamander, A. macrodactylum experienced a $14.5 \%$ decline in hatching rate when exposed to UV compared to UV-shielded counterparts (Blaustein et al.,1997). Although the hatching success was unaffected in both $P$. cruciger and $D$. melanostictus, survival of the tadpoles showed a significant reduction upon exposure in both species. Field experiments conducted in Oregon, USA showed B. boreas and $R$. cascadae exposed to UV had low hatching rates as well as higher mortality (Blaustein et al., 1994). Similarly, embryos of the salamander Ambystoma gracile exposed to UV-B had a higher mortality in addition to lower hatching rates (Blaustein et al., 1996).

However, several studies have shown that exposure of eggs or tadpoles to UV have no effect on hatching success or survival. For example, Langhelle et al. (1999) reported no negative effect on survival or hatching success of Rana temporaria, Bufo bufo, Bufo calamita and Hyla arborea exposed to UV-B radiation. Moreover, mortality among $R$. arvalis eggs and larvae even after the exposure to $1.254-1.584 \mathrm{kJm}^{-2}$ levels was not affected (Pahkala et al., 2001). Similarly, embryos of $R$. temporaria showed neither mortality nor developmental abnormalities upon exposure to weighted doses of $1.19-1.29 \mathrm{kJm}^{-2}$ for 3-15 days (Cummins et al., 1999). Field experiments conducted in Oregon reported that the hatching success of Hyla regilla was not affected upon exposure to UV-B (Blaustein et al., 1994).

Elongation of the growth period was common to the exposed tadpoles of both species. Their metamorphs were significantly smaller in size compared to those in the controls. The longer time taken for metamorphosis and smaller size of adults can have many adverse impacts on their biology and ecology. In the natural context, smaller size at metamorphosis makes anurans less competitive in foraging and other resource utilization, leading to reduced fitness in comparison with the larger individuals (Carey and Bryant, 1995). Nonetheless, delaying metamorphosis may have a crucial impact on amphibian survival, as they often breed in temporary water bodies, particularly in rice fields and human altered habitats (Manamendra- 
Arachchi and Pethiyagoda, 2006), which may dry up before completion of metamorphosis. Rapid colonization, reproduction and growth are important for the survival of organisms living in rapidly changing ecosystems, such as rice fields (Fernando, 1995; Wells, 2007).

A high frequency of malformations was observed in the exposed individuals of both species, edemas in the abdominal region being the most common type. Exposure to UV-B radiation has been reported inducing different types of malformations such as eye-cataracts (Flamarique et al., 2000), edema (Jagger, 1985), tail curvature and abnormal pigmentation (Licht and Grant,1997) in different amphibian species. Similarly, Bufo americanus, Rana clamitans and Rana sylvatica tadpoles have suffered UV-B induced pigmentation followed by direct mortality (Grant and Licht, 1995). Rana pipiens showed induction of bilateral ectromelia and ectrodactyly in the hind limbs under UV exposure (Ankley et al.,1998). Ankley and colleagues (2002) further reported a significant elevation (21-53\%) of hind limb and digit malformations of $R$. pipiens upon exposure to laboratory UV-B (290-320 $\mathrm{nm})$ radiation.

Most of the malformations consisted of deletions and truncations where missing and shortened digits and digit segments were observed. There are a few studies reporting the occurrence of eye abnormalities such as varying degrees of micro/anophilmia $(80 \%)$ reported by Ankley et al. 2002. Jablonski (1998) reported UV induced neural tube defects due to folate deficiency resulted by UV light induced photolysis of folate. Moreover, Worrest and Kimelderf (1976) reported malformations such as epidermal hyperphasia, lordosis (curvature of the vertebral column), abnormal development of presumptive cornea together with high mortality levels in $B$. boreas upon laboratory exposure to UV radiation (290-315 nm with $7.5 \mathrm{kJm}^{-2}-41 \mathrm{kJm}^{-2}$ ).

Even though, some species such as Oregon cascade amphibians are able to develop normally under intense solar radiation (Kats et al., 2000) but some other species such as $R$. casecadae and $B$. boreas suffer high mortality due to radiation (Blaustein et al., 1999). Damage caused by UV radiation is dependent on intrinsic factors such as photolyase levels, egg laying behaviors and pigmentation (Licht and Grant, 1997) and abiotic factors such as water depth, turbidity or vegetation cover, which alter the amount of radiation received by the animals in their habitat. Hence, some species are more vulnerable to radiation even though they share the same habitat with other low-sensitivity species. The physical nature of the amphibian egg is an important factor in the context of radiation damage. The jelly capsule around the egg is an effective covering from UV-B radiation (Grant and Licht, 1995). Eggs with 5-6 $\mathrm{mm}^{2}$ jelly cover of $3 \mathrm{~mm}$ thickness absorb 6-14 \% of UV B radiation in $B$. americanus, $R$. aurora and $R$. sylvatica eggs (Grant and Licht, 1995). In addition to the above, life history characteristics such as length of the development period is an important factor. Tadpoles of D. melanostictus were smaller than the tadpoles of $P$. cruciger at the time of hatching. Fast -living species (Jonhson et al., 2012) which attain smaller body sizes at metamorphosis appear to suffer more compared to those that develop slowly and attain larger body sizes at metamorphosis. Between the two species tested, D. melanostictus is a fast living species $(45 \pm 5$ days for the completion of metamorphosis) compared to the slow-developing $P$. cruciger $(60 \pm 7.5$ days for the completion of metamorphosis). Hence, $P$. cruciger seems to have more time to repair UV $B$ radiation related damage, and hence suffer less mortality, compared to the common toad.

\section{REFERENCES}

Ankley, G. T., Diamond, S. A., Tietge, J. E., Holocombe, G. W., Jensen, K. M., Defoe, D. L, Peterson, R. (2002). Assessment of the risk of solar ultraviolet radiation to amphibians; Dose-dependent induction of hind limb malformations in Northern leopard frog (Ranapipiens) Environmental Science and Technology 36: 2853-2858.

Ankley, G. T., Tietge, J. E., DeFoe, D. L., Jensen, K. M., Holcombe, G. W., Durham, J. E., Diamond, S.A (1998). Effects of ultraviolet light and methoprene on survival and development of Ranapipiens. Environmental Toxicology and Chemistry 17: 2530-2542.

Blaustein, A. R., Hays, T. B., Hoffman, P. D., Chivers, D. P., Kiesecker, J. M., Leonard, W. P., (1999). DNA repair and resistance to UV$\mathrm{B}$ radiation in Western spotted frogs. Ecological Applications 9: 1100-1105.

Blaustein, A. R., Hoffman, P. D., Hokit, D. G., Kiesecker, J. M., Walls, S. C. and Hays, J. B. (1994). UV repair and resistance to solar UV$\mathrm{B}$ in amphibian eggs: a link to population decline? Proceedings of National Academy of Science USA 91: 1791-1795.

Blaustein, A. R., Hoffman, P. D., Kiesecher, J. M. 
and Hays, T. B. (1996) DNA repair activity and resistance to solar UV-B radiation in eggs of the red legged frog. Conservation Biology 10: 1398-1402.

Blaustein, A. R., Kiesecker, J. M., Chivers, D. P. and Anthony, R. H. (1997). Ambient UV-B radiation causes deformities in amphibian embryos. Proceedings of the National Academy of Science, USA 94: 13735-13737.

Blaustein, A. R. and Johnson, P. T. J. (2003). The complexity of deformed amphibians. Frontiers in Ecology and Environment 1: 8794.

Carey, C. and Bryant, C. J. (1995). Possible interrelations among environmental toxicants, amphibibian development and decline of amphibian populations. Environmental Health Perspective 130 (suppl 4):13-17.

Cummins, L. P., Greenslade, P. D., McLeod, A. R. (1999). A test of the effect of supplemental UV-B radiation on the common frog, Ranatemporaria L., during embryonic development. Global Change Biology 5: 471479.

Fernando, C. H. (1995). Rice fields are aquatic, semi-aquatic, terrestrial and agricultural: A complex and questionable limnology. In: K. H. Timotius and F. Goltenboth (eds.) Tropical Limnology 1:121-148.

Flamarique, I. N., Ovaska, K. and Davis, T. (2000). UV-B induced damage to the skin and ocular system of amphibians. Biological Bulletin 199: 187-188.

Formicki, G., Zamachowski, W. and Stawarz, R, (2003), Effects of UV-A and UV B on oxygen consumption in common toad (Bufobufo) tadpoles. Journal of Zoology 259: 317-326.

Grant, K. P. and Licht, L. E. (1995). Effects of ultraviolet radiation on life-history stages of anurans from Ontario, Canada. Canadian Journal of Zoology 73: 2292-2301.

Hatch, A. C. and Blaustein, A. R. (2000). Combined effects of UV-B, nitrate, and low $\mathrm{pH}$ reduce the survival and activity level of larval Cascades frogs (Ranacascadae). Archives of Environmental Contamination and Toxicology 39: 494-499.

Jablonski, N. G. (1998). Sun, skin color and spina bifida. An exploration of the relationship between ultraviolet light and neural tube defects. Proceedings of Australian Society of Human Biology 5: 455-462.

Jayawardena, U. A., Amerasinghe, P. H. and Rajakaruna, R. S., Laboratory exposure of the tadpoles of Polypedates cruciger and Bufo melanostictusto $254 \mathrm{~nm}$ radiation. (Unpublished observations)

Jayawardena, U. A., Rajakaruna, R. S.,
Navaratne, A., and Amerasinghe, P. H. (2010). Trematode induced malformations in amphibians: effect of infection at pre limb bud stage tadpoles of Polypedates cruciger Blyth. Journal of the National Science Foundation 38 (4): 241-248.

Jayawardena, U. A., Navaratne, A. N., Amerasinghe, P. H. and Rajakaruna, R. S. (2011) Acute and chronic toxicity of four commonly used agricultural pesticides on the common toad, Bufo melanostictus. Journal of the National Science Foundation 39 (3): 267276.

Jayawardena, U. A., Rajakaruna, R. S., Navaratne, A. N., and Amerasinghe, P. H (2010) Toxicity of pesticides exposure on common hourglass tree frog, Polypedates cruciger. International Journal of Agriculture and Biology 12: 641-648.

Jayawardena, U. A., Tkach, V. V., Navaratne, A.N., and Amerasinghe, P.H and Rajakaruna, R.S. (2013) Malformations and mortality in the Asian Common Toad induced by exposure to pleurolophocercouscercariae (Trematoda: Cryptogonimidae). Parasitology International 62: 256-262

Johnson, P. T. J., Lunde, K. B., Ritchie, E. G., and Launer, A.E. (1999). The effect of trematode infection on amphibian limb development and survivorship. Science 284 (5415): 802-804.

Johnson, P. T. J., Rohr, J. R., Hoverman, J. T., Kellermanns, E., Bowerman, J. and Lunde, K. B. (2012) Living fast and dying of infection: host life history drives interspecific variation in infection and disease risk. Ecology Letters 15: $235-42$.

Jurkiewicz, B. A. and Buettner, G. R. (1994). Ultraviolet light induced free radical formation in skin- an electron paramagnetic resonance study. Photochemistry and Photobiology 59: 1-4.

Kats, L. B., Kiesecker, J. M., Chiver, D. P. and Blaustein, A. R. (2000). Effects of UV-B radiation on anti-predator behavior in three species of amphibians. Ethology 106: 921931.

Kerr, J. and McElroy, C. (1993). Evidence for large upward trends of ultraviolet-B radiation linked to ozone depletion. Science 262: 10321034.

Kiesecker, J. M. (2002). Synergism between trematode infection and pesticide exposure: A link to amphibian limb malformations in nature? Proceedings of the National Academy of Science, USA 99: 9900-9904.

Langhelle, A., Lindell, M. J. and Nystrom, P. (1999). Effects of Ultraviolet radiation on amphibian embryonic and larval 
development. Journal of Herpetology 33: 449-456.

Licht, L. E. and Grant, K. P. (1997). The effects of ultraviolet radiation on the biology of amphibians. American Zoologist 37: 137145.

Manamendra-Arachchi, K. and Pethiyagoda, R. (2006). Amphibians of Sri Lanka. WHT publications (pvt) Ltd. Colombo. Sri Lanka.

Pahkala, M. A., Laurila, L. O., Bjorn Merila, J. (2001). Effects of Ultraviolet radiation and $\mathrm{pH}$ on early development of the moor frog Ranaarvalis. Journal of Applied Ecology 38: 628-636.

Rajakaruna, R. S., Piyatissa P.M.J.R., Jayawardena, U. A., Navaratne, A. N. and Amerasinghe, P. H. (2008). Trematode infection induced malformations in the common hourglass tree frogs. Journal of Zoology 275: 89-95.

Rajakaruna, R. S., Samarawickrama, V. A. M. P. K. and Ranawana, K. B. (2007). Amphibian decline and possible etiologies: the case for Sri Lanka. Journal of the National Science
Foundation, Sri Lanka 35: 3-8.

Sokal, R. J. and Rohlf, F. J. (1995). Biometry, $3^{\text {rd }}$ edn. W. H. Freeman Company, New York.

Wells K.D. (2007). The Ecology and Behaviour of Amphibians. The University of Chicago Press, USA.

Wijesinghe, M. R., Jayatillake, B. A. D. M. C. and Ratnasooriya, W. D. (2011). Solar radiation alters toxicity of carbofuran: Evidence from empirical trials with Duttaphyrnus melanostictus. Journal of Tropical Forestry and Environment 1: 48-55.

Worrest, R. C. and Kiemeldof, D. J. (1976). Distortions in amphibian development induced by Ultraviolet B enhancement (290$315 \mathrm{NM})$ of a simulated solar spectrum. Photochemistry and Photobiology 24: 377382.

WOUDC (2007). World Ozone and Ultraviolet Radiation Data Centre- [Meteorological Service of Canada]-http://www.woudc.org. Accessed on May 2007. 